\title{
Prevention of Pulmonary Edema after Minimally Invasive Cardiac Surgery with Mini-Thoracotomy Using Neutrophil Elastase Inhibitor
}

\author{
Satoshi Yamashiro, MD, PhD, Ryoko Arakaki, MD, Yuya Kise, MD, and Yukio Kuniyoshi, MD
}

\begin{abstract}
Purpose: Unilateral re-expansion pulmonary edema (RPE) is a rare but one of the most critical complications that may occur after re-expansion of a collapsed lung after minimally invasive cardiac surgery (MICS) with mini-thoracotomy.

Methods: We performed a total of 40 consecutive patients with MICS by right minithoracotomy with single-lung ventilation between January 2013 and June 2016. We divided the patients into control group $(n=13)$ and neutrophil elastase inhibitor group $(n=27)$. Neutrophil elastase inhibitor group received continuous intravenous infusion of neutrophil elastase inhibitor at $0.2-0.25 \mathrm{mg} / \mathrm{kg}$ per hour from the start of anesthesia until extubation during the perioperative period.

Results: There were no relations with operative time, cardiopulmonary bypass (CPB) time, aortic clamp time, and intraoperative water valances for postoperative mechanical ventilation support time. Compared with the neutrophil elastase inhibitor group, the control group had significantly higher initial alveolar-arterial oxygen gradient and significantly lower initial ratio of partial pressure of arterial oxygen to fraction of inspired oxygen at the intensive care unit (ICU). The control group had significantly longer postoperative mechanical ventilation support time and hospital stay compared with the neutrophil elastase inhibitor group. Conclusions: Neutrophil elastase inhibitor may have beneficial effects against RPE after MICS with mini-thoracotomy.
\end{abstract}

Keywords: re-expansion pulmonary edema, minimally invasive cardiac surgery, neutrophil elastase inhibitor

\section{Introduction}

Recently, minimally invasive cardiac surgery (MICS) with single-lung ventilation has been reported to have excellent outcomes. ${ }^{1,2)}$ MICS has several advantages, such as early social rehabilitation, cosmetic merit, and

Department of Thoracic and Cardiovascular Surgery, Graduate School of Medicine, University of the Ryukyus, Nakagami-gun, Okinawa, Japan

Received: June 7, 2017; Accepted: August 3, 2017

Corresponding author: Satoshi Yamashiro, MD, PhD. Department of Thoracic and Cardiovascular Surgery, University of the Ryukyus, 207 Uehara, Nishihara-cho, Nakagami-gun, Okinawa 903-0215, Japan Email: y3104@med.u-ryukyu.ac.jp

(C)2018 The Editorial Committee of Annals of Thoracic and Cardiovascular Surgery. All rights reserved. reduced risk of serious infection, but rare complications can occur. ${ }^{1-5)}$ Recent publications reported on patients who developed unilateral lung edema after MICS that required intraoperative lung collapse. ${ }^{6-9)}$

Unilateral re-expansion pulmonary edema (RPE) is a rare but potentially life-threatening event that may occur after re-expansion of a collapsed lung.

Since 2014, we started to routinely use a specific neutrophil elastase inhibitor (sivelestat) to prevent reperfusion lung injury during MICS. Neutrophil elastase inhibitor has already been used clinically as an agent for acute lung injury or acute respiratory distress syndrome, and is known to simultaneously attenuate ischemia and reperfusion injury in the lung. ${ }^{10-12)}$ In this study, we aimed to evaluate the efficacy of neutrophil elastase inhibitor for lung injury secondary to RPE after MICS 
by comparing perioperative data between patients with and without neutrophil elastase inhibitor treatment.

\section{Patients and Methods}

Between January 2013 and June 2016, a total of 40 consecutive patients were performed MICS by right mini-thoracotomy with single-lung ventilation. The first 13 patients underwent MICS without the use of neutrophil elastase inhibitor, unless they developed persistent hypoxemia due to RPE. These patients were assigned to the control group $(n=13)$. After the experiences with patients suffering postoperatively from a RPE, we modified the perioperative management in 2014 and, from then on, have administered a neutrophil elastase inhibitor. Owing to this circumstance, our analysis had a before-after design. After January 2014, all patients who underwent MICS received intravenous infusion of neutrophil elastase inhibitor (sivelestat) at $0.2-0.25 \mathrm{mg} / \mathrm{kg}$ per hour from the start of anesthesia until extubation in the perioperative period. Sivelestat solution was prepared by diluting $300 \mathrm{mg}$ of sivelestat in $200 \mathrm{~mL}$ of saline. These patients were assigned to the neutrophil elastase inhibitor group $(\mathrm{n}=27)$. The study protocol was approved by the local ethics committee, who waived the need to obtain patient consent as it was a retrospective study design. Since 2016, all patients for neutrophil elastase inhibitor group provide informed consent prior to receiving this drug. So, patients were not randomly assigned to the study drug.

Each patient was transferred to the intensive care unit (ICU) after surgery and was subjected to intensive respiratory and circulatory management. Postoperatively, pain therapy was undertaken by continuous administration of $0.2 \%$ ropivacaine through a catheter localized in the intercostal groove at the level of incision with intravenous injection of an opioid. Postoperative respiratory management was performed by ICU physician (anesthesiologist). Patients were extubated after they had successfully performed a spontaneous breathing trial. In our institution, extubation criteria were as follows: 1) they were hemodynamically stable and neurologically adequate; 2) non-bleeding (mediastinal drainage less than $100 \mathrm{~mL}$ in the last hour); 3) respiratory rate $<30 / \mathrm{min}$; and 4) alveolar-arterial oxygen difference $\left(\mathrm{A}-\mathrm{aDO}_{2}\right)$ $<350 \mathrm{mmHg}$ and partial pressure of arterial oxygen to fraction of inspired oxygen ratio (PFR) $>350$. These criteria were constant throughout the study period.

Mean arterial pressure was maintained between 90 and $120 \mathrm{mmHg}$ and heart rate between 80 and 110 beats per minutes and cardiac index $(\mathrm{CI}) \geq 2.2 \mathrm{~L} / \mathrm{min} / \mathrm{m}^{2}$ and systemic vascular resistance index between 1500 and 2000 dyne-s- $\mathrm{m}^{2} / \mathrm{cm}^{5}$ which were calculated by the Vigileo monitor with the 1.07 version of the software (Edwards Lifesciences, Irvine, CA, USA).

Hemodynamic stability was maintained that blood pressure (BP) 100-130 mmHg, heart rate (HR) 80-100 beats per minutes, and urine output $100-150 \mathrm{~mL} / \mathrm{h}$ with the aid of inotropes (catecholamine), vasopressors (nitroglycerin), landiolol hydrochloride, furosemide, and carperitide at the discretion of the cardiac surgeon at the ICU.

Chest radiographs were routinely obtained after arrival on the ICU and the next morning. Unilateral RPE was diagnosed by radiologist as a new, almost all one-sided pulmonary edema that was apparent on chest radiography and computed tomography after operation (Fig. 1). We did not include asymptomatic and uneventful cases, such as pulmonary atelectasis. In addition, we performed chest computed tomography (CT) in all patients at least in postoperative day (POD) 7.

Arterial blood samples were collected at the ICU for gas analysis. $\mathrm{A}-\mathrm{aDO}_{2}$ and the ratio of partial pressure of arterial oxygen $\left(\mathrm{PaO}_{2}\right)$ to fraction of inspired oxygen $\left(\mathrm{FiO}_{2}\right)(\mathrm{PFR})$ were calculated.

The primary end point was defined as a newly developed RPE which was radiographically evident within $24 \mathrm{~h}$ after surgery. In our institution, postoperative respiratory management was performed by ICU physician (anesthesiologist) strictly. So, we considered that postoperative ventilation time reflects recovery of lung function.

The patients in this study did not receive preoperative nor postoperatively corticosteroids.

\section{Surgical technique}

After intubation with a double-lumen endotracheal tube, all patients underwent standardized intraoperative managements. Anesthesia was induced with sufentanil, etomidate, and pancuronium and maintained with sevoflurane and supplemental sufentanil, as required. All patients were monitored intraoperatively by transesophageal echocardiography. Intraoperative fluid management was not standardized, but patients usually received less than $1 \mathrm{~L}$ of crystalloid before undergoing cardiopulmonary bypass $(\mathrm{CPB})$.

We performed the surgical procedure through the fourth or fifth anterolateral intercostal space with a 5- to 6-cm skin incision as usual manner. $\mathrm{CPB}$ was 

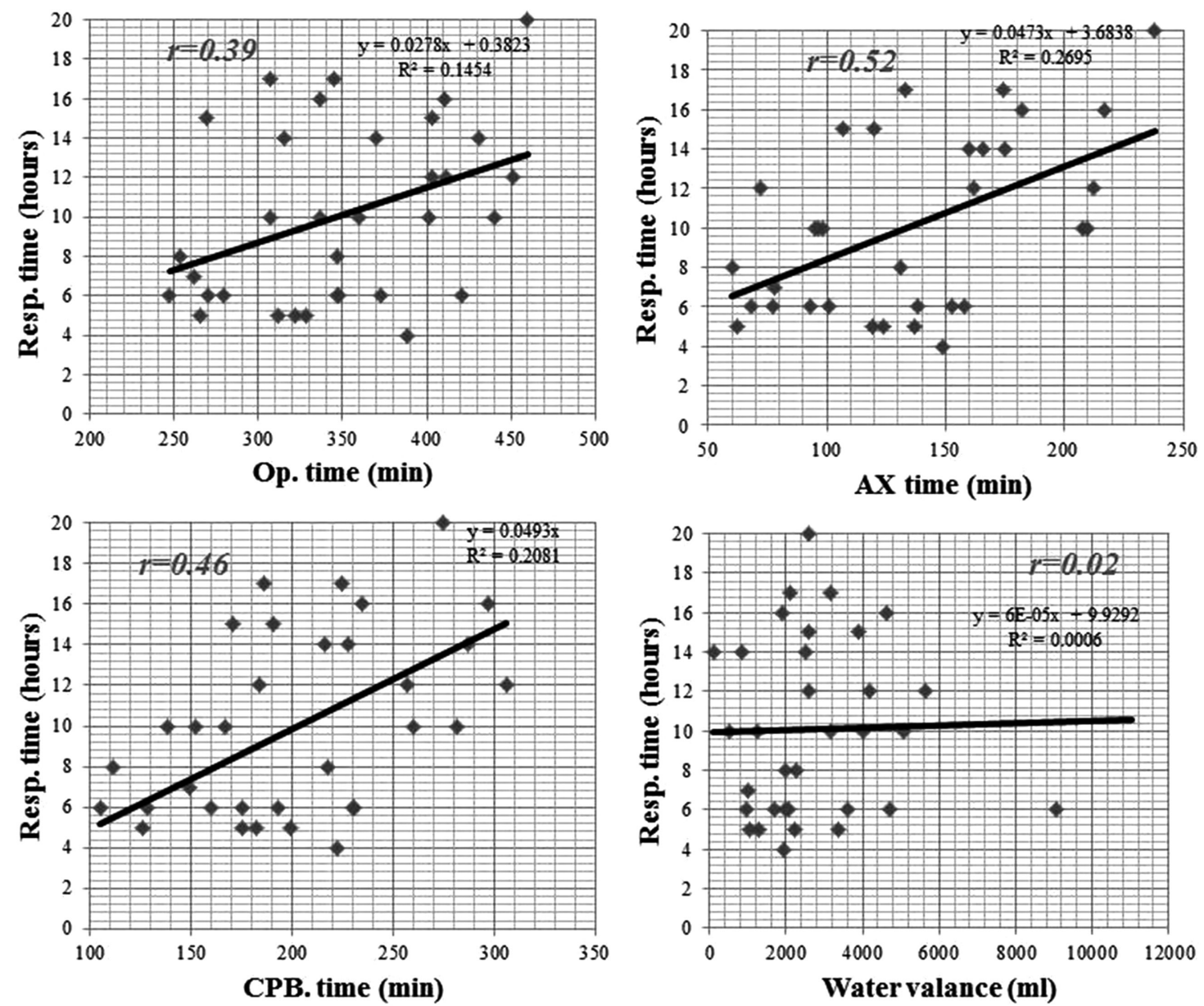

Fig. 1 Correlations with operation time (A), CPB time (B), and aortic clamp time (C) and also intraoperative water valances (D) postoperative mechanical ventilation support time. There were no correlations with perioperative factors for postoperative mechanical ventilation support time. CPB: cardiopulmonary bypass

established via the right femoral artery and vein. We used a vacuum-assisted system for venous drainage. Superior vena cava drainage was additionally used only when right atrial surgeries required, including tricuspid valve or Maze procedure. Cardiac arrest was obtained by administration of an antegrade and/or retrograde cardioplegic solution through a catheter inserted in the aortic root or coronary sinus after direct aortic cross-clamping. A left atrial vent tube was inserted from the fifth intercostal space, and the thoracic cavity was filled with carbon dioxide from the side tube of the 5-mm port. After completion of standard MICS procedures, de-airing was established by the aortic root and left atrial vent.

For respiratory management, single-lung ventilation was started just before opening the visceral pleura. Lung ventilation was stopped after establishment of CPB. Double-lung ventilation was re-started after weaning off
$\mathrm{CPB}$. During surgical procedure, positive end-expiratory pressure (PEEP) of the left lung was kept at $8-10 \mathrm{cmH}_{2} \mathrm{O}$.

Double-lumen endotracheal tube changed into a single-lumen endotracheal tube at the end of surgery. A right-sided chest tube was inserted and connected to an evacuation system with a continuous suction of -15 mbar.

Postoperative ventilation mode was stetted as pressure control ventilation ranged $8 \mathrm{~mL} / \mathrm{kg}$ with $5-10 \mathrm{cmH}_{2} \mathrm{O}$ PEEP. The patients were extubated in the postoperative period after completion of the institutional ICU weaning protocol as described.

Intraoperative intravenous fluid infusion was individually adjusted for each patient to maintain hemodynamic index such as a CI $>2 \mathrm{~L} / \mathrm{min} / \mathrm{m}^{2}$ with central venous pressure nearby $10 \mathrm{mmHg}$. Hemodynamic stability was maintained with the aid of inotropes (catecholamine), vasopressors (nitroglycerin), landiolol hydrochloride and carperitide at the discretion of the anesthesiologist. 
Table 1 Demographic data of patients who underwent minimally invasive cardiac surgery by right mini-thoracotomy with single-lung ventilation $(N=40)$

\begin{tabular}{|c|c|c|c|}
\hline & Control & $\begin{array}{l}\text { Neutrophil elastase } \\
\text { inhibitor }\end{array}$ & $\mathrm{P}$ \\
\hline Patients number & 13 & 27 & \\
\hline Age (years) & $56.9 \pm 16.3$ & $52.8 \pm 14.5$ & 0.42 \\
\hline Gender (male/female) & $9 / 4$ & $20 / 7$ & 0.7 \\
\hline \multicolumn{4}{|l|}{ Disease } \\
\hline Congenital (ASD) & 2 & 2 & 0.43 \\
\hline LA tumor (myxoma) & 2 & 0 & $0.04 *$ \\
\hline Mitral valve regurgitation & 9 & 25 & 0.053 \\
\hline \multicolumn{4}{|l|}{ Comorbidity } \\
\hline CVD & 1 & 1 & 0.59 \\
\hline VSA & 0 & 1 & 0.48 \\
\hline Post-IE & 1 & 2 & 0.97 \\
\hline \multicolumn{4}{|l|}{ Performed operation } \\
\hline ASD closure & 2 & 2 & 0.43 \\
\hline Tumor resection & 2 & 0 & $0.04 *$ \\
\hline MVR & 1 & 3 & 0.74 \\
\hline MVP & 8 & 22 & 0.17 \\
\hline Concomitant procedure & 1 & 5 & 0.37 \\
\hline Maze & 0 & 3 & 0.21 \\
\hline TAP & 1 & 2 & 0.97 \\
\hline \multicolumn{4}{|l|}{ Respiratory function } \\
\hline$\% \mathrm{VC}(\%)$ & $98.3 \pm 15.9$ & $107.4 \pm 13.1$ & 0.06 \\
\hline $\mathrm{FEV}_{1.0} \%(\%)$ & $80.6 \pm 12.7$ & $81.3 \pm 5.6$ & 0.81 \\
\hline Smoking & 2 & 3 & 0.70 \\
\hline Operation time (minutes) & $385.8 \pm 100.5$ & $323.4 \pm 70.8$ & 0.06 \\
\hline CPB time (minutes) & $201.8 \pm 86.1$ & $184.3 \pm 57.9$ & 0.45 \\
\hline Aortic clamp time (minutes) & $118.2 \pm 59.9$ & $120.5 \pm 51.1$ & 0.90 \\
\hline Blood transfusion (ml) & $1539.1 \pm 445.5$ & $1282.8 \pm 523.6$ & 0.14 \\
\hline No blood transfusion & $3(23.1 \%)$ & $13(48.1 \%)$ & 0.13 \\
\hline
\end{tabular}

$*<0.05$. ASD: atrial septal defect; LA: left atrium; CVD: cerebrovascular disease;

VSA: vasospastic angina; IE: infectious endocarditis; MVR: mitral valve replacement; MVP: mitral valve repair; TAP: tricuspid valve annuloplasty; VC: vital capacity;

$\mathrm{FEV}_{1.0}$ : forced expiratory volume in 1 second; CPB: cardiopulmonary bypass

Blood or platelet was transfused when a hemoglobin value less than $9 \mathrm{~g} / \mathrm{dL}$ and a platelet count less than $60,000 / \mathrm{dL}$, respectively. In the ICU, crystalloid infusion was started at $80 \mathrm{~mL} / \mathrm{h}$.

\section{Statistical analysis}

Continuous data are expressed as mean \pm standard deviation (SD), and categorical variables are expressed as ratios (\%). Characteristics between the two groups were compared using Student's t test and Statview 5.0. P values less than 0.05 were considered statistically significant.

\section{Results}

\section{Patient demographics}

Table 1 shows the demographic data of the 40 patients who underwent MICS by right mini-thoracotomy, including 2 patients with cardiac tumor, 4 with congenital heart disease, and 34 with valvular heart disease (4 mitral valve replacement [MVR], 30 mitral valve repair [MVP]). Concomitant tricuspid annuloplasty and full maze procedure were performed in three and three patients, respectively. The mean age of the study population was $53.8 \pm 14.8$ years, with a preponderance of men $(n=29)$. There were no significant differences in major preoperative data and preoperative spirometry between the control and neutrophil elastase inhibitor groups.

\section{Postoperative data}

There were no correlations with operative time, CPB, aortic clamp time, and intraoperative water valances for postoperative mechanical ventilation support time (Fig. 1). There were strong correlations between initial $\mathrm{A}-\mathrm{aDO}_{2}$ and PFR with ventilation support time (Fig. 2). 


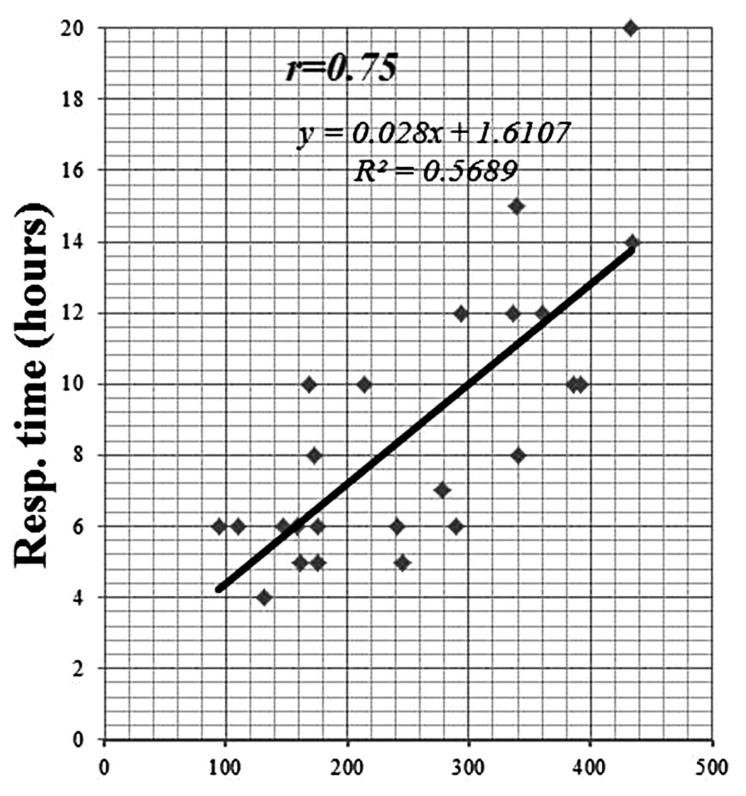

Alveolar-arterial oxygen difference $\mathbf{A - a ~} \mathrm{DO}_{2}(\mathbf{m m H g})$

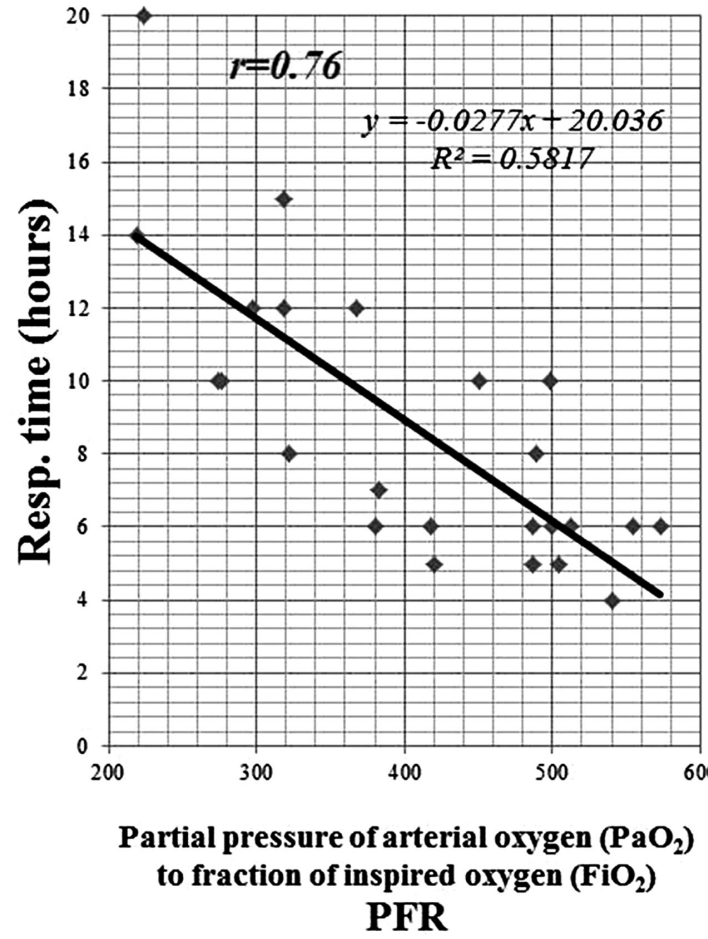

PFR

Fig. 2 Correlations between initial $\mathrm{A}-\mathrm{aDO}_{2}(\mathbf{A})$ and $\mathrm{FiO}_{2}$ ratio (PFR) (B) with ventilation support time. There were strong correlations between initial $\mathrm{A}-\mathrm{aDO}_{2}$ and PFR with ventilation support time. $\mathrm{A}-\mathrm{aDO}_{2}$ : alveolar-arterial oxygen difference; $\mathrm{FiO}_{2}$ : fraction of inspired oxygen; PFR: partial pressure of arterial oxygen to fraction of inspired oxygen ratio

Table 2 shows the comparison between the two groups. Compared with the neutrophil elastase inhibitor group, the control group had significantly higher initial $\mathrm{A}-\mathrm{aDO}_{2}(\mathrm{P}=0.003)$ and significantly lower initial PFR $(\mathrm{P}=0.006)$ at the ICU. Before extubation, $\mathrm{A}-\mathrm{aDO}_{2}$ and PFR were not significantly different in the control group and neutrophil elastase inhibitor group. The control group had significantly longer postoperative ventilation time $(\mathrm{P}=0.0006)$ and postoperative hospital stay $(\mathrm{P}=$ 0.01) compared with the neutrophil elastase inhibitor group. Four patients in the control group required ventilator support over 24 hours.

Two patients who developed moderate-grade RPE immediately after MICS-MVP in the control group were given neutrophil elastase inhibitor from POD1 because of non-improving respiratory condition. Although the duration of operation and CPB in case 1 (360 minutes and 183 minutes, respectively) was relatively short, RPE occurred on day 1 after surgery (Figs. 3A and 3B). After ventilator support and conservative management, including administration of neutrophil elastase inhibitor, but without steroid use, these patients gradually improved and were extubated on
POD3. For case 1, RPE completely resolved on chest radiography and computed tomography at 6 months after operation (Figs. 3C and 3D). Mortality and major morbidities, except respiratory disorder, were not observed in this series.

\section{Discussion}

RPE remains to be a rare and potentially harmful complication that occurs when a collapsed lung is re-expanded during treatment of conditions, such as hemopneumothorax and large pleural effusion, after lobectomy or even during single-lung ventilation. ${ }^{7,9)}$ Recently, Keyl et al. ${ }^{8)}$ described that $7.9 \%$ incidence of radiographically evident RPE after MICS. They reported that among total number of MICS patients, 1.5\% developed clinical symptoms. On the other hand, Tutschka et al. reported that RPE after MICS is common with $25 \%$ incidence. ${ }^{13)}$ In our study, incidence of RPE was 5.0\%. We considered that symptomatic RPE occurred after MICS is relatively rare.

RPE was reported to be unlikely to occur when the period of lung collapse was less than 3 days. ${ }^{2,14)}$ However, it can be infrequently observed after open heart 
Table 2 Postoperative data of patients who underwent minimally invasive cardiac surgery by right mini-thoracotomy with single-lung ventilation $(N=40)$

\begin{tabular}{lccc}
\hline & Control (13) & $\begin{array}{c}\text { Neutrophil elastase } \\
\text { inhibitor (27) }\end{array}$ & $\mathrm{P}$ \\
\hline Complications & & & \\
Bleeding & 1 & 2 & 0.97 \\
A-V block (PM implant) & 1 & 1 & 0.59 \\
Mediastinal hematoma & 1 & 3 & 0.14 \\
Elevation of diaphragm & 2 & 0 & 0.70 \\
Ventilator support $<24$ hours & 4 & $245.3 \pm 79.8$ & $0.0005^{*}$ \\
Initial A-aDO $($ mmHg) & $353.7 \pm 128.4$ & $414.7 \pm 84.3$ & $0.003^{*}$ \\
Initial PFR & $308.0 \pm 130.2$ & $10.5 \pm 5.0$ & $0.0006^{*}$ \\
Ventilation time (hours) & $24.9 \pm 18.6$ & $214.6 \pm 66.9$ & 0.31 \\
A-aDO ${ }_{2}$ at extubation (mmHg) & $235.4 \pm 45.6$ & $436.7 \pm 41.6$ & 0.13 \\
PFR at extubation & $405.0 \pm 89.7$ & $20.9 \pm 7.3$ & $0.01^{*}$ \\
Hospital stay (days) & $28.0 \pm 6.6$ & 0.6 & \\
\hline
\end{tabular}

$*<0.05$. A-V block: atrio-ventricular block; PM: pacemaker; $\mathrm{A}-\mathrm{aDO}_{2}$ : alveolar-arterial oxygen difference; PFR: partial pressure of arterial oxygen to fraction of inspired oxygen ratio
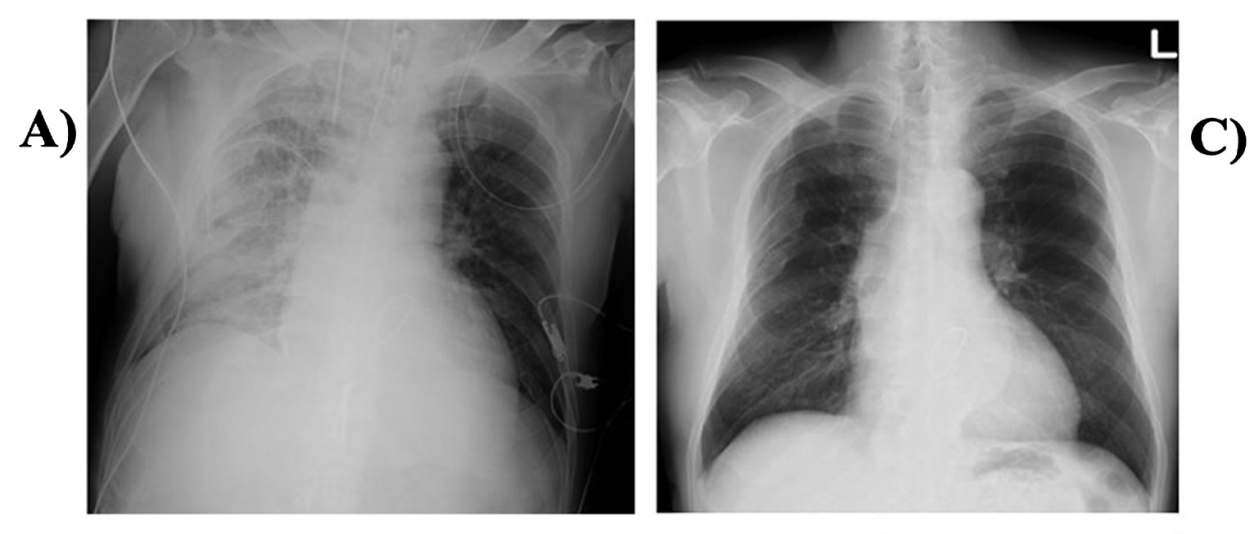

\section{B)}
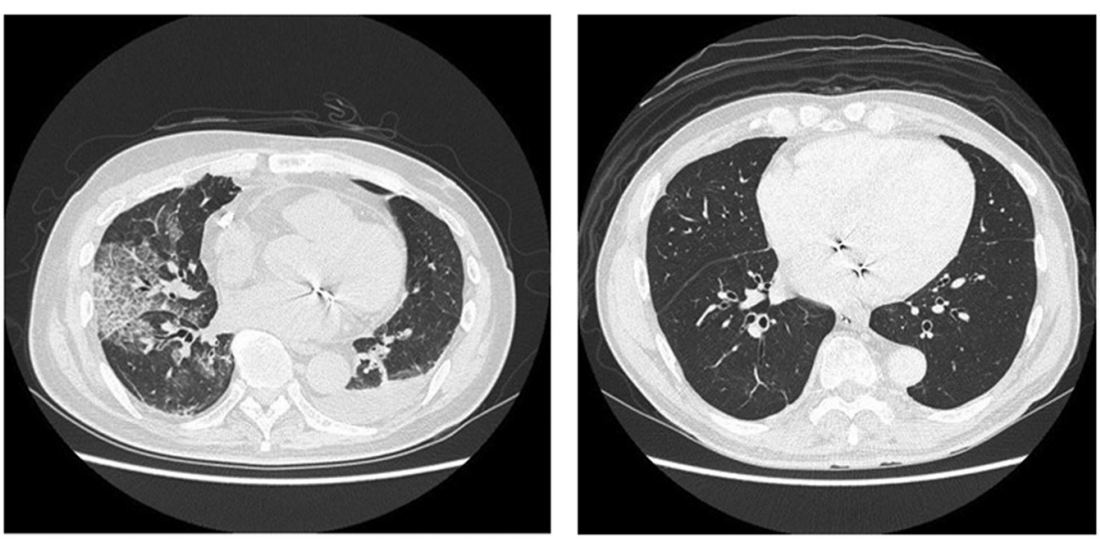

Fig. 3 Imaging findings 1 day after in a 59-year-old male (Case 1) who underwent minimally invasive cardiac surgery (A and $\mathbf{B}$ ). (A) Chest radiography 1 day after operation shows unilateral pulmonary edema on the right. (B) Computed tomography shows obvious unilateral change with alveolar consolidation on the right. Imaging findings 6 months after minimally invasive cardiac surgery (C and D). (C) Chest radiography shows improvement in the unilateral right-sided pulmonary edema. (D) Computed tomography shows disappearance of the unilateral changes and alveolar consolidation. 
surgery with a short period of one-lung ventilation. In our experience, RPE occurred 1 day after surgery in case 1 even if the duration of operation (360 min) and CPB (183 $\mathrm{min}$ ) were relatively short (Fig. 3). Figure 1 shows that there were no correlations with operation time, $\mathrm{CPB}$ time and aortic clamp time and also intraoperative water valances and postoperative mechanical ventilation support time. We believed that it is important to reduce CPB time and duration of lung collapsing. However, we think that there are other mechanisms of occurrence of RPE.

Although mechanical stress and histologic abnormalities of the pulmonary microcirculation were reported as mechanisms of RPE, the risk factors after cardiac surgery with single-lung ventilation are still unknown. ${ }^{8,15,16)}$ It is well known that CPB induces a systemic inflammatory response called post-pump syndrome. Although some organs can be involved, the lung is often the first organ damaged, making this a major complication of CPB. ${ }^{17)}$ It has been reported that activated neutrophils that accumulate in the lung and release chemical mediators, such as neutrophil elastase, play an important role in post-pump syndrome. Eguchi et al. ${ }^{18)}$ described that neutrophil plays a key role in lung re-expansion capillaries injury. Neutrophil elastase is released when neutrophils are activated by several types of stimuli, including ischemia. ${ }^{19)}$ Neutrophil elastase is significantly harmful enzyme, which develops to mediate neutrophil extravasation, tissue infiltration, and endothelial cell injury.

A novel neutrophil elastase inhibitor, sivelestat sodium hydrate, has been clinically used in the respiratory field and was initially considered to reduce neutrophil-mediated acute lung injury, including inflammatory or post-perfusion lung injury. ${ }^{10,11,19-21)}$ Recent studies have shown that sivelestat reduced and prevented tissue ischemia and reperfusion injury in several organs. ${ }^{11,22)}$ The beneficial effects of neutrophil elastase inhibitor on post-perfusion lung and ischemia-reperfusion and endothelial cell injuries have been demonstrated in several experiments. ${ }^{17}$ )

We experienced two mild RPE cases after MICS. Fortunately, they recovered after using sivelestat and were extubated on POD3. We have not encountered postoperative lung injury since 2014, when we started to use sivelestat routinely to prevent reperfusion lung injury during MICS. Moreover, ventilation time and hospital stay were reduced. The analysis of our results may have practical implications in going evolution in these severe cases. Our experimental study suggested that neutrophil elastase inhibitor has beneficial effects on lung injury caused by RPE after MICS.
Owing to the difficulties of providing conclusive evidence with an observational study, prospective studies are needed to gain further insight into the development of RPE after MICS. Further prospective study would be necessary including the measurement of chemical mediators such as cytokines (neutrophil elastase and interleukin-6 or interleukin-8) and reactive oxygen species (hydrogen peroxidase, hydroxyl radical, nitric oxide, and peroxynitrite) to clarify the effectiveness of neutrophil elastase inhibitor during MICS. Moreover, we would be identifying the optimal timing of neutrophil elastase inhibitor treatment for preservation on lung injury caused by RPE after MICS.

\section{Limitations}

The primary limitation of our report is that this is a non-randomized and retrospective analysis of data and we relied on the medical record to appropriately classify patients as having a post-obstructive etiology of acute pulmonary edema. Moreover, the present study investigated only a few patients, and thus we cannot reach a definite conclusion.

\section{Disclosure Statement}

The authors declared no potential conflicts of interest with respect to the research, authorship, and/or publication of this article.

\section{References}

1) Ding C, Wang C, Dong A, et al. Anterolateral minithoracotomy versus median sternotomy for the treatment of congenital heart defects: a meta-analysis and systematic review. J Cardiothorac Surg 2012; 7: 43.

2) Irisawa Y, Hiraoka A, Totsugawa T, et al. Re-expansion pulmonary oedema after minimally invasive cardiac surgery with right mini-thoracotomy. Eur J Cardiothorac Surg 2016; 49: 500-5.

3) Hiraoka A, Kuinose M, Chikazawa G, et al. Minimally invasive aortic valve replacement surgery: comparison of port-access and conventional standard approach. Circ J 2011; 75: 1656-60.

4) Glauber M, Miceli A, Gilmanov D, et al. Right anterior minithoracotomy versus conventional aortic valve replacement: a propensity score matched study. J Thorac Cardiovasc Surg 2013; 145: 1222-6.

5) Seeburger J, Borger MA, Falk V, et al. Minimal invasive mitral valve repair for mitral regurgitation: results 
of 1339 consecutive patients. Eur J Cardiothorac Surg 2008; 34: 760-5.

6) Shires AL, Green TM, Owen HL, et al. Case 4-2009. Severe reexpansion pulmonary edema after minimally invasive aortic valve replacement: management using extracorporeal membrane oxygenation. J Cardiothorac Vasc Anesth 2009; 23: 549-54.

7) Madershahian N, Wippermann J, Sindhu D, et al. Unilateral re-expansion pulmonary edema: a rare complication following one-lung ventilation for minimal invasive mitral valve reconstruction. J Card Surg 2009; 24: 693-4.

8) Keyl C, Staier K, Pingpoh C, et al. Unilateral pulmonary oedema after minimally invasive cardiac surgery via right anterolateral minithoracotomy. Eur J Cardiothorac Surg 2015; 47: 1097-102.

9) Neustein SM. Reexpansion pulmonary edema. J Cardiothorac Vasc Anesth 2007; 21: 887-91.

10) Hoshi K, Kurosawa S, Kato M, et al. Sivelestat, a neutrophil elastase inhibitor, reduces mortality rate of critically ill patients. Tohoku J Exp Med 2005; 207: 143-8.

11) Kambe M, Bessho R, Fujii M, et al. Sivelestat reduces myocardial ischemia and reperfusion injury in rat hearts even when administered after onset of myocardial ischemia. Interact Cardiovasc Thorac Surg 2009; 8: 629-34.

12) Isikawa $N$, Oda $M$, Kawaguchi $M$, et al. The effects of a specific neutrophil elastase inhibitor (ONO-5046) in pulmonary ischemia-reperfusion injury. Transpl Int 2003; 16: 341-6.

13) Sohara Y. Reexpansion pulmonary edema. Ann Thorac Cardiovasc Surg 2008; 14: 205-9.

14) Tutschka MP, Bainbridge D, Chu MW, et al. Unilateral postoperative pulmonary edema after minimally invasive cardiac surgical procedures: a case-control study. Ann Thorac Surg 2015; 99: 115-22.

15) Iqbal M, Multz AS, Rossoff LJ, et al. Reexpansion pulmonary edema after VATS successfully treated with continuous positive airway pressure. Ann Thorac Surg 2000; 70: 669-71.

16) Suzuki S, Niikawa H, Shibuya J, et al. Analysis of edema fluids and histologic features of the lung in reexpansion pulmonary edema during video-assisted thoracoscopic surgery. J Thorac Cardiovasc Surg 2002; 123: 387-9.

17) Fujii M, Miyagi Y, Bessho R, et al. Effect of a neutrophil elastase inhibitor on acute lung injury after cardiopulmonary bypass. Interact Cardiovasc Thorac Surg 2010; 10: 859-62.

18) Eguchi $T$, Hamanaka $K$, Kondo $R$, et al. Lung re-expansion following one-lung ventilation induces neutrophil cytoskeletal rearrangements in rats. Ann Thorac Cardiovasc Surg 2014; 20: 276-83.

19) Iwamoto $S$, Higashi A, Ueno T, et al. Protective effect of sivelestat sodium hydrate (ONO-5046) on ischemic spinal cord injury. Interact Cardiovasc Thorac Surg 2009; 8: 606-9.

20) Kawabata K, Suzuki M, Sugitani M, et al. ONO5046, a novel inhibitor of human neutrophil elastase. Biochem Biophys Res Commun 1991; 177: 814-20.

21) Wakayama F, Fukuda I, Suzuki Y, et al. Neutrophil elastase inhibitor, sivelestat, attenuates acute lung injury after cardiopulmonary bypass in the rabbit endotoxemia model. Ann Thorac Surg 2007; 83: 153-60.

22) Okajima K, Harada N, Uchiba M, et al. Neutrophil elastase contributes to the development of ischemiareperfusion-induced liver injury by decreasing endothelial production of prostacyclin in rats. Am J Physiol Gastrointest Liver Physiol 2004; 287: G1116-23. 